\title{
Provincial Carotid Endarterectomy Outcomes
}

\author{
Thomas E. Feasby, Hude Quan, William A. Ghali
}

\begin{abstract}
Background: Outcomes must be measured as a first step toward improving performance. We sought to measure the national and provincial outcomes from carotid endarterectomy (CE) and explain provincial differences. Methods: We analyzed a large Canada-wide administrative hospital discharge database of all patients, except those in Québec, receiving CE in 1994-1997 and used logistic regression for risk adjustment to measure adverse outcomes nationally and by province. Our main outcome measures were in-hospital stroke and/or death. Results: A total of 14,268 patients underwent CE in the years 1994-1997. The overall death rate was $1.3 \%$ and the combined stroke and/or death rate was $4.1 \%$. There was a trend towards improvement over the four years. The provinces of Saskatchewan and Newfoundland had significantly higher adverse event rates for the risk-adjusted combined outcome measure. Conclusions: The outcome of CE in Canada is good and showed improvement over four years. However, significant differences in provincial outcomes were found. This suggests that regionalization across provincial boundaries may be needed to promote higher surgeon and hospital case volumes and thus improve outcomes.
\end{abstract}

RÉSUMÉ: Résultats provinciaux de l'endartérectomie carotidienne. Introduction: La première étape dans un processus visant à améliorer la performance est l'évaluation des résultats. Notre but était d'évaluer les résultats nationaux et provinciaux de l'endartérectomie carotidienne (EC) et d'expliquer les différences interprovinciales. Méthodes: Nous avons analysé une base de données administrative pancanadienne de congés hospitaliers de tous les patients, sauf de ceux du Québec, ayant subi une EC entre 1994 et 1997. Nous avons utilisé l'analyse de régression logistique pour ajuster les données pour le niveau de risque afin d'analyser les résultats défavorables nationaux et provinciaux. Notre principale mesure des résultats était l'accident vasculaire cérébral (AVC) et/ou le décès pendant l'hospitalisation. Résultats: Au total, 14268 patients ont subi une EC entre 1994 et 1997. Le taux de mortalité a été de $1,3 \%$ et le taux combiné d'AVC et/ou de décès a été de 4,1\%. Ces taux présentaient une tendance à la baisse au cours de ces quatre années. La Saskatchewan et Terre-Neuve avaient un taux significativement plus élevé d'incidents thérapeutiques en ce qui concerne la mesure des résultats combinés, ajustée pour le niveau de risque. Conclusions: Les résultats de l'EC sont bons au Canada et se sont améliorés au cours des quatre années de l'étude. Cependant, il existe des différences interprovinciales significatives, ce qui suggère que la régionalisation sans égard aux limites territoriales provinciales pourrait être nécessaire pour promouvoir un volume plus élevé de cas par chirurgien et par hôpital et ainsi améliorer les résultats.

Can. J. Neurol. Sci. 2002; 29: 333-336

Carotid endarterectomy (CE), an operation to remove atheromatous narrowing from the cervical internal carotid artery, is an important means of secondary stroke prevention. It has been used with increasing frequency in Canada in recent years, ${ }^{1,2}$ since randomized controlled clinical trials (RCTs) have shown that the procedure is efficacious in symptomatic ${ }^{3}$ and perhaps asymptomatic $^{4,5}$ patients with carotid stenosis. The benefit demonstrated in those trials was dependent upon the low rates of peri-operative mortality and morbidity achieved. Questions have been raised about whether such low rates can be duplicated outside RCTs, in the real world. ${ }^{5,6}$ Thus, it is essential to measure the performance of $\mathrm{CE}$ to ensure that it is being done with minimum mortality and morbidity and is thus conferring maximum benefit.
Despite continued widespread use of CE in Canada, ${ }^{2}$ there is a general lack of information on short-term outcomes associated with $\mathrm{CE}$ in this country. To address this knowledge gap we have conducted a national study of the performance of CE in Canada, measuring the in-hospital death and stroke rates over a four year period and comparing the results from the various provinces.

From the Departments of Clinical Neurosciences (TEF), Medicine (WAG) and Community Health Sciences (WAG, HQ), and the Centre for Health and Policy Studies (WAG), University of Calgary and the Calgary Health Region, Calgary, Alberta, Canada.

ReCeived April 8, 2002. ACCEPTED infinalform August 12, 2002. Reprint requests to: Thomas E. Feasby, Department of Clinical Neurosciences, Foothills Hospital, 1403 - 29th St NW, Calgary, AB, Canada T2N 2 T9. 


\section{MethodS}

Hospital discharge data on all CEs were obtained from the Canadian Institute for Health Information (CIHI). This is a national database that includes information on all hospital discharges in Canada, except for the province of Québec which does not report data to CIHI. The database does not include information on indications for surgery. Patients in the other nine provinces and two territories for the fiscal years 1994-1997 were identified by searching the database for those years using code 50.12 of the Canadian Classification of Procedures. ${ }^{7} \mathrm{We}$ excluded those patients who had coronary artery bypass grafting (CABG) and $\mathrm{CE}$ at the same admission.

\section{Study Variables}

The outcomes of interest were the observed and risk adjusted rates of in-hospital stroke and/or death. Stroke, as a complication, was defined using ICD9 codes 433, 434, 436, or 438 when the diagnosis-type indicators available in Canadian administrative data indicated that the stroke had occurred during hospitalization. We have shown previously that the use of these indicators improves the detection of complications in administrative data studies. ${ }^{8}$ In addition, a postoperative stroke was considered to have occurred when ICD9 code 997.0 was present.

The sociodemographic variables studied were age and sex. To define co-morbidity variables that may predict outcome, we used the Deyo coding system ${ }^{9}$ that is adapted for use with the ICD-9CM coding manual to identify the 17 comorbidities (see the Analysis section) that make up the Charlson comorbidity index, ${ }^{10}$ an index widely used for risk adjustment in outcome studies. In addition to the Charlson index, we also identified prior CABG (ICD9CM code V458.1) admission through the emergency room (as an indicator of urgency) and unstable angina (ICD9CM code 411.1) as baseline variables that may be associated with adverse postoperative events.

\section{Analysis}

We initially performed chi-square analyses and t-tests to explore associations between outcomes and age, sex and comorbidities. Then, logistic regression was used to identify multivariate predictors of the composite outcome of in-hospital stroke and/or death and to calculate adjusted rates of this outcome. Four variables, mild liver disease, moderate to severe liver disease, dementia and HIV were excluded from multivariate analysis because they were rarely present and because no outcome events occurred in patients with these variables. The final model included patient age and sex, admission through emergency, chronic lung disease, diabetes, diabetes with complications, neoplastic disease, hemiplegia, myocardial infarction (old and recent), rheumatologic disease, peptic ulcer disease, chronic renal failure, peripheral vascular disease, metastatic disease, congestive heart failure, unstable angina, and prior $\mathrm{CABG}$.

We used this risk-adjustment model to calculate the predicted probability of in-hospital stroke and/or death for each patient who underwent $\mathrm{CE}$. We then averaged these predicted probabilities in a given province $(\mathrm{E})$. The observed rate of stroke and/or death $(\mathrm{O})$ divided by the expected rate $(\mathrm{E})$ generated an $\mathrm{O} / \mathrm{E}$ ratio for each province. The adjusted provincial rates of stroke and/or death were calculated by multiplying each province's $\mathrm{O} / \mathrm{E}$ ratio by the overall in-hospital stroke and/or death rate.

We calculated the adjusted stroke and/or death rates for each year and each province over four years. Adjusted national rates over the four years were plotted and tested for trend by linear regression. We tested for differences in the adjusted stroke and/or death rate between provinces using the differences in the $-2 \log$ likelihood chi-square statistic for models with, versus those without, the provinces in the model. The observed versus expected adverse outcome rates were plotted by province.

\section{Results}

A total of 14,268 patients underwent CE in the years 19941997 in Canada, excluding Québec. No cases were done in the Yukon or Northwest Territories. The socio-demographic characteristics and comorbidities of the population are shown in the Table. Also shown are the numbers of cases and their

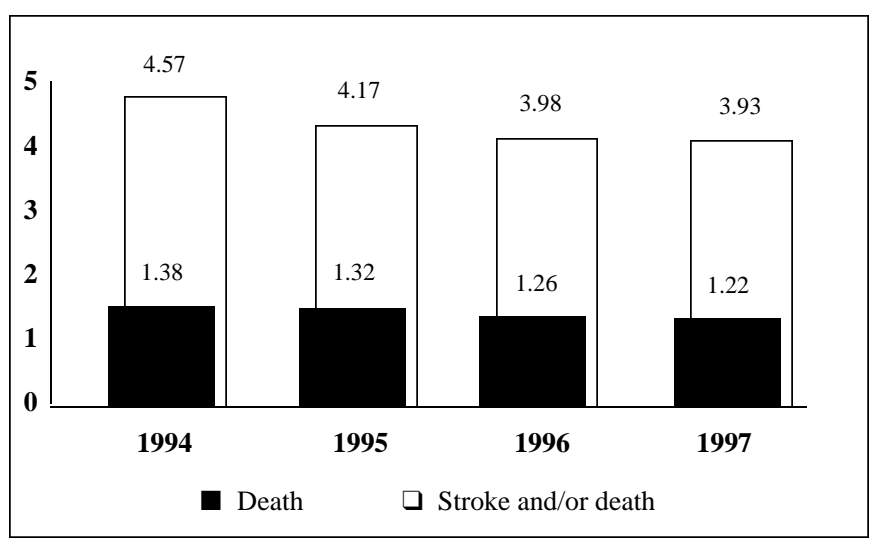

Figure 1: The adjusted national death rate (solid bars) and combined stroke and/or death rate (open bars) by year.

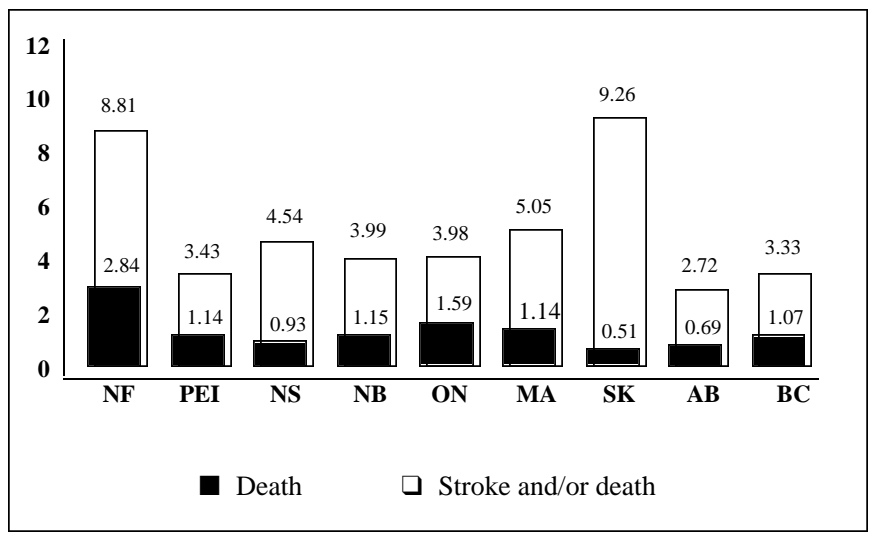

Figure 2: The adjusted provincial death rates (solid bars) and combined stroke and/or death rates over four years. 
Table: Characteristics of patients undergoing carotid endarterectomy in 1994-1997. $(\mathrm{N}=14,268)$

\section{Characteristic}

Mean age ( \pm Standard Deviation)

$68.7(8.6)$

n $(\%$ of 14,268$)$

\section{Sex (female)}

Diabetes

Emergency admission

Old myocardial infarction

Peripheral vascular disease

Chronic pulmonary disease

Previous CABG

Hemiplegia or paraplegia

Congestive heart failure

Neoplasm

Unstable angina

Diabetes with complications

Chronic renal disease

Recent myocardial infarction

Rheumatological disease

Peptic ulcer disease

Dementia

Metastatic disease

Mild liver disease

Moderate to severe liver disease

HIV

Fiscal year

1994
1995
1996
1997

1994

1996

1997

Province

British Columbia
Alberta
Saskatchewan
Manitoba
Ontario
New Brunswick
Nova Scotia
Prince Edward Island

Newfoundland

$5007(35.1)$
$2032(14.2)$
$1287(9.0)$
$955(6.7)$
$928(6.5)$
$907(6.4)$
$840(5.9)$
$373(2.6)$
$231(1.6)$
$159(1.1)$
$145(1.0)$
$140(1.0)$
$97(0.7)$
$95(0.7)$
$69(0.5)$
$68(0.5)$
$26(0.2)$
$14(0.1)$
$6(0.04)$
$0(0)$
$0(0)$

$2831(19.8)$

3705 (26.0)

3897 (27.3)

3835 (26.9)

$3121(21.9)$

$1161(8.1)$

$513(3.6)$

$1085(7.6)$

$6673(46.8)$

$687(4.8)$

$523(3.7)$

$196(1.4)$

$309(2.2)$

percentages done in each province. The overall national death rate was $1.3 \%$. The postoperative stroke rate was $3.4 \%$ and the combined stroke and/or death rate was $4.1 \%$.

Figure 1 shows the national adverse outcome rates over the four years studied. There was a steady decrease in both the adjusted rates for death $(\mathrm{p}=0.0041)$ and the combination of stroke and/or death, although the latter was not quite statistically significant $(\mathrm{p}=0.0672)$.

Figure 2 shows the adverse outcome rates over four years for each province. Newfoundland and Saskatchewan had significantly higher combined stroke and/or death rates than the

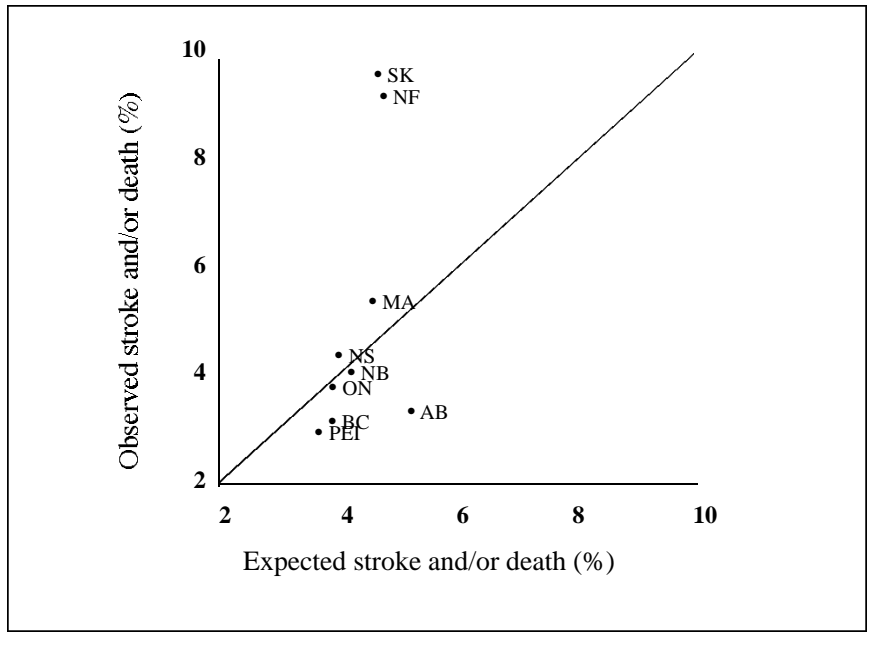

Figure 3: The observed versus expected combined stroke and/or death rates $(\%)$ by province over four years.

other provinces $(\mathrm{p}<0.001)$. None of the provinces was significantly worse than the others for mortality. The plot of the observed versus the expected combined adverse outcome rate (Figure 3) shows that all provinces are clustered along the line of identity except Newfoundland and Saskatchewan.

\section{DISCUSSION}

The national mean mortality rate for Canada was $1.3 \%$, comparable to the rate of $1.1 \%$ found in the major North American CE trial in symptomatic patients, ${ }^{3}$ although our series contained an unknown proportion of asymptomatic patients, presumably at lesser risk. ${ }^{4}$ Importantly, the national rates of adverse outcomes for CE for 1994-1997 showed a steady and statistically significant decline

The provincial comparisons showed that in all but two provinces, CE was performed as well as predicted by our riskadjustment model. However, both Saskatchewan and Newfoundland had results for the combined outcome of stroke and/or death that were significantly worse than the other provinces and worse than predicted. We explored this difference further to try to explain the deviation. We tested for differences between Saskatchewan and Newfoundland and the other provinces, using the chi-square test, for several hospital and surgeon attributes. We found that these two provinces were significantly $(\mathrm{p}<0.001)$ more likely to have CE cases done in low volume hospitals ( $<150$ cases/four years), by low volume surgeons ( $<15$ cases/four years) and by general surgeons (rather than vascular surgeons or neurosurgeons). Their cases were also less likely to have been done in hospitals that participated in the two major North American randomized trials of CE (NASCET ${ }^{3}$ and $\mathrm{ACAS}^{4}$ ). We have shown recently, using this same national database, that each of these attributes predicts a worse combined adverse outcome rate of stroke and/or death ${ }^{11}$ after CE.

There have been few previous studies examining national outcome rates from surgical procedures in Canada and only a 
few provincial studies. The Institute for Clinical Evaluative Sciences has published practice atlases for Ontario, showing regional rates of procedures and outcomes. ${ }^{12,13}$ One national study of CABG showed a declining mortality rate between $1992 / 3$ and $1995 / 6^{14}$. Substantial variation in adjusted mortality rates was also seen between provinces. Interestingly, Newfoundland was also worse than expected for CABG mortality, perhaps for similar reasons.

Our study has several limitations. We used administrative data, which is known to be less accurate for recording complications than mortality, ${ }^{15}$ although our earlier work demonstrates that $\mathrm{CABG}$ report cards are similar across different data sources. ${ }^{16}$ Also, in this study, we lack the full Canadian profile of $\mathrm{CE}$ because we were unable to examine data from Québec. Our results likely underestimated the negative outcomes somewhat, since we measured stroke and/or death only until hospital discharge, not for 30 postoperative days as in the RCTs. Also, the recording or stroke as an outcome in administrative data is likely to be incomplete. In addition, our definition of postoperative stroke is open to some debate. We used a combination of specific stroke codes and a nonspecific code (997) for neurological complications. The latter may not always represent stroke, but we opted to use it because we anticipated that many hospitals code postoperative strokes this way. Because of these factors, the rates of postoperative stroke we found are lower than found in recent studies of CE using chart review. ${ }^{17,18}$ Also, using administrative data, we were unable to determine the proportion of cases that were asymptomatic. Since the adverse outcome rate for asymptomatic cases is generally lower than for symptomatic cases, ${ }^{4}$ it is possible that the provinces that showed poorer outcomes had a higher proportion of symptomatic patients, although we think this is unlikely. It is also possible that an increasing proportion of asymptomatic patients treated could explain some of the overall improvement in outcomes we saw nationally over four years.

Finally, while we were able to explain some of the differences between provinces on the basis of volume and specialist issues, there are likely other relevant process issues that we did not examine. These limitations underline the ongoing need to develop prospective national registries for $\mathrm{CE}$ and other surgical procedures.

The differences in outcome from CE in our interprovincial comparisons suggest that there may be differences in the quality of care. The factors we have previously identified as being predictive of worse outcome, low case volumes for hospitals and surgeons, CE by general surgeons and lack of clinical trial participation, all appear to be relevant in the two provinces whose performance was worse than expected. The two provinces that had the highest adverse event rates both have difficult geographical challenges and may also have difficulty with retention of specialists who care for patients undergoing CE. According to the Donabedian model of quality of care, ${ }^{19}$ structural issues such as these may have negative effects on outcomes. Sub-optimal outcomes in such circumstances should, therefore, not be viewed as a negative reflection on provider performance. On the contrary, providers working in such environments should be congratulated for their efforts to provide high quality care despite challenging circumstances. Nevertheless, our findings suggest that consideration be given to regionalization of care for $\mathrm{CE}$ without regard for provincial boundaries, to ensure adequate case volumes for both surgeons and hospitals.

\section{ACKNOWLEDGEMENTS}

Supported by a research grant from the Heart and Stroke Foundation of Alberta, the Northwest Territories and Nunavut. Dr. Ghali is supported by a Population Health Investigator Award from the Alberta Heritage Foundation for Medical Research and holds a Canada Research Chair.

\section{REFERENCES}

1. Tu JV, Hannan EL, Anderson GM, et al. The fall and rise of carotid endarterectomy in the United States and Canada. New Eng J Med 1998;339:1441-1447.

2. Feasby TE, Quan H, Ghali WA. Geographic variation in the rate of carotid endarterectomy in Canada. Stroke 2001;32:2417-2422.

3. North American Symptomatic Carotid Endarterectomy Trial Collaborators. The benefit of carotid endarterectomy in symptomatic patients with moderate and severe stenosis. NEJM 1998;339:1415-1425.

4. Executive Committee for the Asymptomatic Carotid Atherosclerosis Study. Endarterectomy for asymptomatic carotid artery stenosis. JAMA1995;273:1421-1428.

5. Feasby TE. Endarterectomy for asymptomatic carotid stenosis in the real world. Can J Neurol Sci 2000;27:95-96.

6. Barnett HJM, Eliasziw M, Meldrum H, Taylor D. Do the facts and figures warrant a 10 -fold increase in the performance of carotid endarterectomy on asymptomatic patients? Neurology 1996;46:603-608.

7. Canadian Classification of Diagnostic, Therapeutic and Surgical Procedures. Ottawa: Statistics Canada, 1986, cat. no. 82-562E.

8. Ghali WA, Quan H, Brant R. Risk adjustment using administrative data. Impact of a diagnosis-type indicator. J Gen Intern Med 2001;16:519-524.

9. Deyo R, Cherkin D, Ciol M. Adapting a clinical comorbidity index for use with ICD-9-CM administrative databases. J Clin Epidemiol 1992;45:613-619.

10. Charlson M, Pompei P, Ales K, et al. A new method of classifying prognostic comorbidity in longitudinal studies: development and validation. J Chron Dis 1987;40:373-383.

11. Feasby TE, Quan H, Ghali WA. Hospital and surgeon determinants of carotid endarterectomy outcomes. In press, Arch Neurol 2002.

12. Naylor CD, Anderson GM, Goel V. Patterns of health care in Ontario. The ICES Practice Atlas. Vol. 1. Ottawa: Canadian Medical Association; 1994.

13. Naylor CD, Slaughter P(Eds). Cardiovascular Health and Services in Ontario: an ICES Atlas. 1st ed. Toronto: ICES; 1999.

14. Ghali WA, Quan H, Brant R. Coronary artery bypass grafting in Canada: national and provincial mortality trends, 1992-1995. Can Med Assoc J 1998;159:25-31.

15. Williams JI, Young W. Appendix 1. A summary of studies on the quality of health care administrative databases in Canada. In: Goel V, Williams JI, Anderson GM, Blackstien-Hirsch P, Fooks C, Naylor CD (Eds). Patterns of Health Care in Ontario. The ICES Practice Atlas. 2nd ed. Ottawa: Canadian Medical Association; 1996:339-345.

16. Ghali WA, Rothwell DM, Quan H, Brant R, Tu JV. A Canadian comparison of data sources for coronary artery bypass surgery outcome 'report cards'. Am Heart J 2000;140:402-408.

17. Kucey DS, Bowyer B, Iron K, et al. Determinants of outcome after carotid endarterectomy. J Vasc Surg 1998;28:1050-1058.

18. Kresowik TF, Bratzler D, Karp HR, et al. Multistate utilization, processes, and outcomes of carotid endarterectomy. J Vasc Surg 2001;33:227-235.

19. Donabedian A. The Definition of Quality and Approaches to its Assessment. Health Administration Press, Ann Arbor, Michigan, 1980 . 